\title{
John L. Cotter Award in Historical Archaeology
}

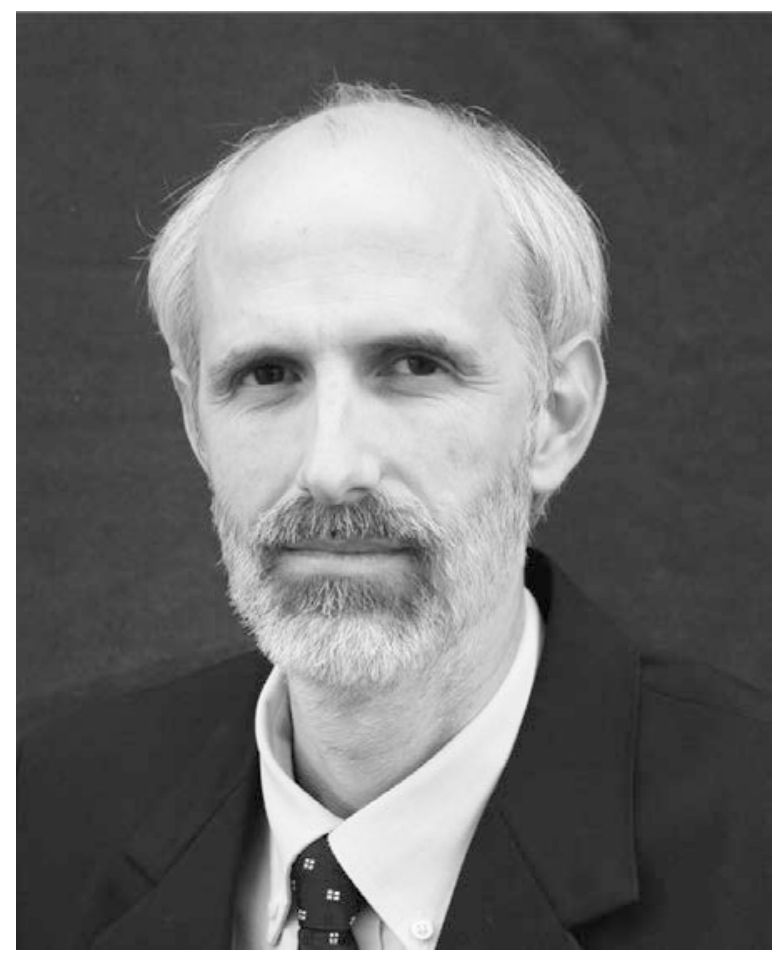

James Davidson

James Davidson of the University of Florida is the recipient of the Society for Historical Archaeology's 2012 John L. Cotter Award for his exemplary scholarship in African diaspora studies and historical archaeology. Dr. Davidson's scholarship confronts the historical roots of race, racism, and cultural distinctions, and critically and systematically partners with African diasporan descendant communities. Dr. Davidson's research is thorough and meticulous, and his work is distinguished by its ambitious research questions that confront contemporary and historical injustices with exceptionally rich and complex data sets. His commitment to a politically engaged archaeology that partners with descendant communities and integrates diasporan scholarly voices into his research distinguish his work in historical archaeology.

The first prominent area of Dr. Davidson's scholarship has focused on historical mortuary and bioarchaeological studies. Davidson is one of the leading scholars on the bioarchaeology and cultural dimensions of burial practices among people of African descent. Davidson has demonstrated impressive depth and range in field experience, with investigations of 12 cemeteries and over 1,200 burials. Much of his work has focused on the massive late-19th-century mortuary assemblage from Freedman's Cemetery in Dallas, Texas, one of the largest African American skeletal collections excavated in the United States. His analysis used carefully argued and complex archaeological data to underscore the brutality of racism in late-19th- and early-20th-century American life, confronting the concrete implications of racism on the very bodies of African Americans. He developed an exceptionally precise and comprehensive burial chronology in a 619-page master's thesis and 
his even more monumental dissertation (Davidson 2004a), Mediating Race and Class through the Death Experience: Power Relations and Resistance Strategies of an African-American Community, Dallas, Texas (1869-1907). Davidson examines the death experience of black Texans through the entanglements of race and class revealed in, on the one hand, consumerism and mortuary displays, and, on the other hand, vernacular expressions of African-based spirituality. From a complex range of resources Davidson paints a rich picture of violence and the color line in turn-of-the century Dallas that tracks the rates of gun violence against African Americans, documents the spatial dimensions of gun violence, and underscores the breadth of racist brutality at modest and grand scales alike. For example, he undertook a novel study of 18 anonymous gunshot victims, discovered who they were based on historical research and skeletal analysis, and exposed the root causes of interpersonal violence in early-20th-century Dallas (Davidson 2008). His investigation of the founding of the Baylor School of Medicine revealed an horrific example of structural violence perpetrated against the black community in Dallas, as the school was involved with the turn-ofthe-20th-century theft of black bodies for use as medical cadavers and their illicit disposal (Davidson 2007). The desecration of African American remains for medical dissection, the cemetery's razing in the 1920s, and the paving of neighboring streets with displaced headstones underscores the depth of racist hatred in 20th-century America. In this and his other work, Davidson details the everyday material and social effects of racism with a clever and complex range of material culture and scholarly resources.

A second thread of Davidson's scholarship revolves around the complexities of African cultural persistence, acknowledging the depth of African cultural practice in the New World, yet reflectively examining the ways such cultural traditions were reconfigured in captivity and subsequently freedom. Since 2006, this research has focused on enslaved Africans at the Kingsley Plantation in Florida, where Charles Fairbanks first excavated in the 1960s in an effort to identify African cultural survivals in New World captivity. Fairbanks is often recognized as the first anthropological archaeologist to conduct research on African America, and Kingsley is routinely considered the birthplace of the rich plantation archaeology that followed in the 1970s. Fairbanks concluded that the African cultural practices that came to the New World were radically modified and in some ways symbolically unidentifiable in everyday material culture, but African American spirituality rooted in African cosmologies has remained a well-studied topic since Fairbanks sought to find evidence of it at Kingsley. Davidson has approached Africanisms as "mutable metaphors" that took a variety of material forms departing from the African material styles that Fairbanks had expected, documenting a rich range of previously unrecognized African cultural traditions. For example, he directed analysis of the largest archaeological sample of personal charms worn to ward off witchcraft, all found around necks or ankles in 15 burials in Dallas (Davidson 2004b); he analyzed the enigmatic placement of a single shoe on the lids of coffins as a means to trap evil, a practice based in African cosmology (Davidson 2010); and he has argued that a common form of grave construction in 19th-century America, grave vaulting, is actually a common African mode of burial. Davidson concludes that much of the material data from historical archaeology and Fairbanks's own excavations vindicates Fairbanks's hypothesis that African practices continued in New World captivity.

All of Davidson's work has a clear commitment to responsible stewardship of African American heritage, patient and thoughtful partnering with descendant communities, and a firm acknowledgment of the complications of examining a half-millennium of racism. James respects rigorous "dirt archaeology" and has developed thoughtful, critical, and creative research that reaches well beyond narrow historical archaeological circles. Davidson's focus on public engagement reaches back to the Dallas Freedman's Project and earlier work in Arkansas, so his interest in a truly politically engaged archaeology is central to his vision of the discipline. This research has demanded significant fieldwork and sustained training of many students who share an interest in such scholarship. He has conducted excavations every field season from 2006 through 2011, training over 90 undergraduates and supervising the dissertation research of graduate students who have excavated four slave cabins dating between 1814 and 1839. Davidson has simultaneously maintained an exemplary 
record of disseminating his research findings. Since 2004, Davidson has authored or coauthored 30 papers presented at professional meetings and invited talks. He has published extensively, with three monographs, seven book chapters, and nine articles in print. Finally, on top of his publication, mentoring, and teaching commitments he has consistently remained active in the field, producing original research and admirably balancing his various responsibilities.

Dr. James Davidson is an accomplished scholar who has demonstrated his dedication to historical archaeology both as a student and a professional. His work is representative of the best that our field has to offer in making innovative and socially relevant contributions to historical archaeology, and he has demonstrated that he will continue to contribute significantly to the discipline.

\section{References}

DAVIDSON, JAMEs M.

2004a Mediating Race and Class through the Death Experience: Power Relations and Resistance Strategies of an African-American Community, Dallas, Texas (1869-1907). Doctoral dissertation, Department of Anthropology, University of Texas at Austin. University Microfilms International, Ann Arbor, MI.

2004b Rituals Captured in Context and Time: Charm Use in North Dallas Freedman's Town (1869-1907), Dallas, Texas. Historical Archaeology 38(2):22-54.

2007 "Resurrection Men” in Dallas: The Illegal Use of Black Bodies as Medical Cadavers (1900-1907). International Journal of Historical Archaeology 11(3):193-220.

2008 Identity and Violent Death: Contextualizing Lethal Gun Violence within the African-American Community of Dallas, TX (1900-1907). Journal of Social Archaeology 8(3):321-356.

2010 Keeping the Devil at Bay: The Shoe on the Coffin Lid and Other Grave Charms in Nineteenth and Early Twentieth Century America. International Journal of Historical Archaeology 14(4):614-649.

Paul R. Mullins and Maria Franklin 